\title{
Psychological determinants of information searching activity
}

\author{
L. Gorunova* \\ Journal Production Department, IOS Press, Nieuwe Hemweg 6b, 1013 BG, Amsterdam, The Netherlands \\ Department of Ergonomics and Engineering Psychology, Faculty of Psychology, Saint-Petersburg State \\ University, 7-9 Universitetskaya Nab. ,St. Petersburg, 199034, SPbSU, Russia
}

\begin{abstract}
The paper deals with the application of the activity theory in describing psychological determinants of the information searching activity. The notions of information behavior, information retrieval, information competence, information retrieval activity given in Russian and English scientific literature are compared. The research approach to the information retrieval activity based on the principles developed in the Russian theory of activity is described; and the fundamentals of G. Sukhodolsky's generalized conception of activity are presented for the first time. Analysis of empirical researches showed that specific features of information search depend on how the user evaluates information resources, information, conditions and results of search. Psychological determiners of information search may be detected as the system of evaluative alternatives, which is generated by the user during the process of his experience growth. We discovered that user's evaluation system is also related to his individual typological and personal regulative features and determines the choice of the search strategy.
\end{abstract}

Keywords: Information searching, activity theory, subjective representation

\footnotetext{
${ }^{*}$ Corresponding author. E-mail: 1.gorunova@psy.pu.ru
} 


\section{The problems of studying the psychological determinants of information searching activity}

The topicality of studying the psychological determinants of information searching activity is determined by a large number of informational and technological innovations, computer technology introduction into information retrieval and analysis, and exponential growth of electronic forms of information storage. According to experts, efficient information retrieval is one of the key issues of the present and future centuries. It is not enough for modern people to master information technology and apply it. They need to be able to assess data sources, take into account their limitations and forecast possible consequences of data actions. The main psychological problems of information retrieval technologies usage are known. Users utilize common technologies that do not meet specific activity objectives. Information systems designers declare the unique capabilities of modern technologies, but they emphasize their ineffectiveness when applied. Thus the research objective is to investigate psychological determinants of information retrieval activity promoting the formation of the professional and personal identity of researchers under conditions of contemporary information community. The research is focused on studying the psychological determinants of information activity among researchers. Creative, productive, and estimation abilities of researchers are initiated during the information search.

During the research, a theoretical analysis of modern studies of information retrieval activity was carried out; main approaches to their studies have been identified; peculiarities, content and structure of information retrieval activity of a researcher have been investigated; characteristics of personal and professional identity of a researcher have been studied, and their connection with characteristics of information retrieval activity has been established.
2. Methodological grounds for research of information searching activity

Researching methodology is based by combination theoretical activity studies: S. Rubinstein's concept of the subject of activity [4], the integrated concept of activity by G. Sukhodolskiy [6], Y. Engeström 's theory of activity [1], as well as the information behavior concepts by T. Wilson [7]. The research activity concepts [3], the personal and professional identity concept [5], and the concept of behavior selfregulation types [2] have been of great importance.

\subsection{Basic Terms and Concepts}

The Russian-language academic and research literature uses such corresponding concepts as «информационно-поисковая деятельность», «информационное поведение», «информационный поиск». These concepts are often used as synonyms by the authors. However, they are specific in their own way.

Authors working in the fields of information sciences and library science widely use the concept of «информационное поведение». In the Russian books on library science «информационное поведение» is described as actions, efforts aimed at obtaining, using and creating information. The Russian term «информационное поведение» mainly coincides with the English concept of «information behavior». The concept of «информационный поиск» has two meanings. It denotes an academic and research field of study, as well as the information search process itself. It is a modern rapidly developing interdisciplinary academic and research field which are formed at the joint of various science disciplines like informatics, library science, linguistics, semiotics, and psychology. In this sense the Russian concept of «информационный поиск» corresponds to the English term «Information retrieval». Another meaning of the «информационный поиск» concept denotes actions, methods and procedures allowing to carry out selection of certain information out of a database. Accordingly, «информационный поиск» is understood as a process realized with the help of 
an automated information system. The corresponding English term is the term "information retrieval" introduced by Calvin Mooers in the 1950s. It is necessary to point out that a broad concept of «информационный поиск» in the Russian language is connected not only to computer information systems. Therefore in the broader context the term «информационный поиск» is understood as seeking by any means (an individual may use or not use an information retrieval system). In its broader sense, the Russian term «информационный поиск» corresponds to the English term «information seek».

Psychological aspects of information retrieval by a human being have been investigated in different psychological contexts. Cognitive psychology has been researching the task of visual search, active attention, regularities of information retrieval in memory, looking for solution. Engineering psychology has been researching the structure and dynamics of information retrieval internal processes and the external and internal determinants of the effectiveness of human operator information retrieval. In order to more clearly understand the meaning of the corresponding English concepts, need to refer to the article by $\mathrm{T}$. Wilson defining some of them [1]. Engineering psychology defines information retrieval as detection by an operator of information model elements necessary for solving management problems. The information searching activity structure, in its engineering psychology context, comprises the following actions: signal search in the information field, signal pickup according to the set sample, modification detection in the information field, prioritization of subject to management service.

Information retrieval is regarded as a kind of searching activity. It is performed by man using technical equipment and runs under human-computer interaction. The subject of information searching activity is information objects, i.e. man interacts with a computer acting as a tangible medium or a data transmitter. Viewing information retrieval as a kind of activity, we build upon the methodological approaches developed in the Russian psychological science.

\subsection{The integrated concept of activity by G.V.Sukhodolskiy}

Information searching activity is researched from the point of view of the integrated concept of activity by G. V. Sukhodolskiy (1934 - 2008) [6]. The main peculiarity of this concept is that it determines and structures the aspects of psychological description of activity: morphology, axiology, praxiology and ontology of activity. Such approach allows focusing on a particular aspect, nevertheless retaining understanding and taking into account the system characteristics of the activity under study.

The concept assumptions rest upon four postulates.

The interaction postulate means that an individual interacts with the world in various forms of activity. However, activity is viewed in many aspects: content, structural, functional, genetic, reproductive, productive, in cohesion of the external and internal aspects, cohesion of the mental and non-mental activity. At the same time, psychological regulation acts as an inner mental factor of activity (along with other factors like activity flow conditions, peculiarities of the task in hand etc).

The activity principle postulates that mind is active and has ability for self-evolution. This principle develops the theory of L.S. Vygotsky regarding the social character of higher mental functions and assumes their individual conditionalism and productiveness. The reproductive elements of activity perform the functions of retention and accumulation of social and personal experience. The reproductive elements of activity are aimed at variation of experience. Information searching activity includes elements stipulated by human social experience. Information searching activity includes elements stipulated by individual traits of a person, his personal experience.

The postulate of normability and variability means that activity is equally normative and variable in all its forms and at all levels. Activity normability is expressed by retention of the same aspects of activity without change. Variability means change. The 
processes of retention and alteration of elements in the integral activity go on simultaneously and are closely related. An important consequence of the principle of normability and variability is the thesis on the algorithmic and stochastic character of activity and the necessity to define the constant and the variable of content in the operational aspect of activity. This thesis provides rationale for information searching activity mechanisms research on the grounds of description of constant and variable elements of activity and dynamics of their alteration.

The postulate of analysis and synthesis shows that analyses and synthesis are two aspects of description of any activity. Cohesion of scientific analyses and synthesis assumes determination of a "framework", in respect of which the necessary and the sufficient aspects of description of the activity under study are determined. The basic concepts for description of psychological peculiarities of information searching activity are formulated in the Russian psychology of psychological regulation and compose the assumed organization of the psychological regulation system. These concepts comprise aims of activity, models of significant conditions, programs of performing actions, success criteria, assessment of results, adjustment of the results obtained.

The integrated psychological concept represents activity as a system consisting of four interrelated aspects of description: morphology (composition and structures of activity); axiology (values); praxiology (development and operation), and ontology (fundamentals and principles). We focus on the praxiological aspect of activity description. G. V. Sukhodolskiy views praxiology of activity as description of operation and development of activity. At the same time, the praxiological description includes dynamics of individual activity, self-evolution, integrated nature of activity and activity phylogenesis.

G. V. Sukhodolskiy points out that activity may be viewed as realization of a particular human function. Operation from the perspective of the integrated theory of activity may be viewed in different aspects: physical space-time continuum of activity characte- ristics, technological, informational, mental, sensorimotor, and speech continuum. It allows describing operation in the context of material, energetic and information support of activity. The operational effect is estimated according to the rate, accuracy, reliability and cost-efficiency of the actions and operations carried out. Internally, effectiveness is expresses by a person's content with the process and result of his activity.

We view information searching activity in the psychological continuum of properties. The psychological continuum reflects the motives and objectives, plans and programs of activity, the image and conceptual frameworks of activity. Externally, activity operation is described as successive solution of problems. Internally, this process is interpreted as psychological regulation of activity. Correlation between the internal and the external aspects of activity allows judging the dynamics of mental control of activity according to the dynamics of solution of topical problems by an individual. In case of an individual means of activity, the variable components should include operational images, image and conceptual models of situations, which are formed in the process of performing activity by an individual. On the one hand, they program and regulate actions; on the other hand, they are formed and reformed while performing activity.

Relative to the integrated psychological concept, the information searching activity psychological regulation system should be described as cohesion of the external aspect (actions and operations) and the internal aspect (psychological regulation itself). The information searching activity psychological regulation system should include elements stipulated by human social experience, as well as elements stipulated by a person's individual traits and his personal experience. The information searching activity psychological regulation system should include the constant and the variable elements of activity, and the dynamics of their alteration. The basic concepts for description of the information searching activity psychological regulation system are the fundamental concepts of psychology of regulation: aims of activi- 
ty, models of significant conditions, programs of performing actions, success criteria, assessment of results, adjustment of the results obtained.

\section{The case study of psychological determinants of information searching activity}

In the course of the research features, composition and structure of information retrieval activity have been examined, and the specific character of the researcher's information retrieval activity has been elicited. The characteristic features of personal and professional identity of the researcher as a part of the information community have been examined, and their relation to the characteristic features of information retrieval activity has been ascertained; the psychological determinants and the ways to optimize the information retrieval activity of the researcher have been described. The following methods have been used in the research: interview; 'Information Retrieval' form; «Professional motivation Postgraduate» form; Morosanova V.I., The questionnaire "The style of self-regulation of behavior» [2]; Schneider L., The questionnaire "Professional identity"; 16PF Questionnaire; Twenty Statements Test, Manfred Kuhn \& Thomas McPartland; R. Amthauer, «Intelligence Structure Test Battery» (IST).

\section{Psychological determinants of information searching activity}

It has been established that psychological determinants of information retrieval activity of a users determine their ability to restructure actual data and generate new meanings of activity. Psychological peculiarities of information retrieval activity of a researcher have to do with transformation of the scientific information found into personal professional experience. Psychological determinants of information retrieval activity are interrelated with the nature and status of professional identity of researchers as a part of the information community. Psychological determinants comprise four groups of researcher qualities that make themselves evident in information retrieval activity. 1) Evaluation and content components of activity: understanding of objectives and tasks of scientific activity, motives of the scientific work, evaluation criteria for scientific information. 2) Readiness of a researcher to use information technology, application of sustainable system of techniques and methods of scientific information retrieval. 3) Creative and productive abilities of a researcher - analytical and synthetic abilities and ability to integrate the data found. 4) Regulative qualities - ability to extract significant terms of achieving the purpose of scientific activity and change the behavior respectively.

Optimization of the ways to searching information includes usage of detailed criteria for information sources evaluation, internal retrieval resources selfevaluation, time resources evaluation, and subjective evaluation of retrieval difficulty.

\section{References}

[1] Y. Engeström, Learning by Expanding: An ActivityTheoretical Approach to Developmental Research, OrientaKonsultit, Helsinki, 1987.

[2] V.I. Morosanova, Individual style of self-regulation: the phenomenon, the structure and function in any human activity, Moscow, 2001.

[3] A. N. Poddiakov, Exploratory behavior: strategies for learning, support, opposition, conflict, Moscow, 2006.

[4] S. Rubinstein, Being and Consciousness. Man and world, Peter Publishing House, 2003.

[5] L. B. Schneider, Identity, gender and professional identity: theory and methods of diagnosis, Moscow, 2007.

[6] G. V. Sukhodolskiy, Basics of psychological theory activity, Moskow, LKI, 2008.

[7] T.D. Wilson, Human information behavior, Informing Science $3(2),(2000), 49-56$ 